\title{
64 Dedektörlü Bilgisayarlı Tomografide Kontrast Madde Enjeksiyonu Sonrası Nonfatal Venöz Hava Embolisi Sıklığı ve Lokalizasyonu
}

\author{
Frequency and Localization of Nonfatal Venous Air Embolism After Contrast Substance Injection in 64-Detector
}

Computed Tomography

Fatma Öztürk Keleş

Mustafa Kemal Üniversitesi Tip Fakültesi Radyoloji Anabilim Dalı, Hatay, Türkiye

Correspondence:

Fatma ÖZTÜRK KELES

Mustafa Kemal Üniversitesi

Tip Fakültesi Radyoloji Anabilim

Dalı, Hatay, Türkiye

e-mail: fatma4083@hotmail.com

\section{Özet}

Tanısal ve girişimsel radyolojik işlemlerde kontrast madde verilmesi sırasında venöz hava embolisi nonfatal bir olay olarak görülmektedir. Bu çalı̧̧mada, kontrastlı bilgisayarlı tomografide (BT) nonfatal venöz hava embolisinin sıklığını ve lokalizasyonunun tespit edilmesi amaçlanmıştır. Hastanemiz Radyoloji Ünitesinde 1 Ocak 2019-31 Aralık 2019 tarihleri arasında çekilen 1654 kontrastlı toraks bilgisayarlı tomografi tetkiki intravenöz hava varlığı retrospektif olarak değerlendirildi. Tespit edilen venöz hava embolilerin lokalizasyonu, boyutları, kontrast maddenin hangi taraftan verildiği kaydedildi. Bu çalışmada iatrojenik venöz hava embolisi \%3.14 oranında görülmüștür. En sık görüldüğü lokalizasyon ana pulmoner arter olup (\%1.81) diğer görüldüğü lokalizasyonlar sıklık sırasına göre sol brakiosefalik ven (\%0.66), sol subklavyen ven (\%0.36), sağ brakiosefalik ven (\%0.30), sağ subklavyen ven (\%0.24), sağ ventrikül $(\% 0.18)$ ve sağ atriumdur $(\% 0.18)$. Venöz hava embolisinin boyutlarına bakıldığında $\% 2.5$ oranında küçük, \% 0.50 oranında orta ve $\% 0.12$ oranında büyük hava embolisi görüldü. Radyologlar BT taramada kontrast madde enjeksiyonu sonrası vasküler hava embolisi olabileceğini bilmeli ve dikkatli olmalıdır.

Anahtar Kelimeler: Venöz hava embolisi; bilgisayarlı tomografi; kontrast; iatrojenik

\section{Abstract}

During diagnostic and interventional radiological procedures, venous air embolism is seen as a nonfatal event. In this study, it was aimed to determine the frequency and localization of nonfatal venous air embolism in contrast enhanced computed tomography (CT). 1654 contrast-enhanced thorax computed tomography examinations performed in the Radiology Unit of our hospital between January 1, 2019 and December 31, 2019. The localization and size of the detected venous air emboli and from which side the contrast agent was administered were recorded. In this study, iatrogenic venous air embolism was seen in $3.1 \%$. The most common localization is the main pulmonary artery $(1.81 \%)$ and other localizations in order of frequency are left brachiocephalic vein $(0.66 \%)$, left subclavian vein $(0.36 \%)$, right brachiocephalic vein $(0.30 \%)$, right subclavian vein $(0.24 \%)$, right ventricle ( $0.18 \%$ ) and right atrium $(0.18 \%)$. Looking at the size of the venous air embolism, $2.5 \%$ small, $0.50 \%$ moderate and $0.12 \%$ large air embolism were seen. Radiologists should be aware of the possibility of vascular air embolism after contrast agent injection in CT scanning and should be careful.

Keywords: Venous air embolis; computed tomograph; contrast; iatrogenic 


\section{Giriş}

Venöz hava embolisi (VHE) intravenöz kateterlerin takılması, çıkarılması ve kullanımı gibi medikal durumlarda, travma, cerrahi ve jinekolojik işlemler sırasında olabildiği gibi biyopsi, anjiografi ve kontrastlı görüntüleme gibi radyolojik durumlarda da olabilir (1). Kontrastlı bilgisayarlı tomografi (BT) sonrası görülen VHE, tanısal amaçlı BT'nin giderek artan kullanımı nedeniyle nonfatal olarak görülmeye başlanmıştır (2). BT'de kontrast madde enjeksiyonu sonras VHE insidans1 \%11 ile $\% 23$ arasinda bildirilmiştir (2,3).Genellikle küçük hava kabarcıkları minimal VHE olarak kabul edilir ve klinik olarak önemsizdir (4). VHE'nin çoğu asemptomatik olmakla beraber paradoksal hava embolisi için potansiyel risk oluşturan durumlar vardır. Sağdan sola şant veya pulmoner arterivenöz malformasyon gibi risk faktörü olan hastalarda küçük bir hava embolisinin bile nörolojik defisit için yüksek bir risk olduğu belirtilmiştir (5). Kazara 100 cc hava enjeksiyonu fatal kabul edilmekle beraber vücut pozisyonu, enjeksiyon hizı, enjekte edilen toplam hava miktarı, genel sağlık durumu gibi faktörler fatal VHE'sinde önemli rol oynar $(2,5)$. Genellikle venöz sistemde küçük az miktardaki hava girişi sıklıkla dağılır ve hava embolisi kendiliğinde çözülebilir. Bu nedenle çoğu zaman hastalar özel bir tedavi gerektirmeksizin sadece gözleme alınır (6).

Bu çalışmada, kontrastlı BT'de nonfatal venöz hava embolisinin sıklığını ve lokalizasyonunun tespit edilmesi amaçlanmıştır.

\section{Gereç ve Yöntem}

Hatay Mustafa Kemal Üniversitesi Girişimsel Olmayan Klinik Araştırmalar Etik Kurulu'ndan (14/01/2021 tarihli 22 nolu karar) gerekli izin alınarak yapılan bu çalışmaya, Hatay Mustafa Kemal Üniversitesi Tayfur Ata Sökmen Tip Fakültesi Radyoloji Ünitesinde 1 Ocak 2019-31 Aralık 2019 tarihleri arasında, gündüz 08:00-16:00 saatleri arasında poliklinik ve servislerden çeşitli nedenlerle çekilen 1654 hastanın kontrastlı toraks BT tetkikleri çalışmaya dahil edildi. Görüntüler ünitemizde bulunan 64 dedektörlü
BT (Toshiba Aquilion 64 MDCT, Toshiba Medical Systems, Otawara, Japan) ile alınmıştı. Rutin çekim prokolünde rotasyon süresi $0.75 \mathrm{sn}$, dozu $120 \mathrm{kV}$ ve $250 \mathrm{mAs}$, kolimasyon $64 \times 0.625$, pitch değeri 1.375 ve kesit kalınlığ $5 \mathrm{~mm}$ şeklinde otomatik olarak ayarlanmıştı. Non-iyonik kontrast madde açılan damar yolundan otomatik enjektör (Mallinckrodt Optivantage injection system model) ile $80 \mathrm{~mL} 2.5 \mathrm{~mL} / \mathrm{sn}$ hız ile verilmişti. Çekimler gündüz olduğu için kontrast madde enjeksiyonu tecrübeli aynı iki radyoloji teknisyeni tarafindan verilmişti. Elde edilen görüntüler ünitemizdeki görüntüleme monitörlerindeki Osirix MD (Pixmeo Labs, Geneva, Switzerland) programı ile retrospektif olarak değerlendirildi. Acil servis hastalar1, yakın zamanda travma ve cerrahi geçiren, santral venöz kateteri olan hastalar çalışma dışı bırakıldı. Hastaların yaşları, cinsiyetleri, tespit edilen venöz hava embolisinin lokalizasyonu, boyutu, hangi taraftan kontrast madde verildiği kaydedildi. Boyutu $1 \mathrm{~cm}$ 'nin altında olan küçük, $1-2 \mathrm{~cm}$ arasında olanlar orta ve $3 \mathrm{~cm}$ 'den büyük olanlar büyük hava embolisi olarak kabul edildi (3,7). Elde edilen veriler SPSS Windows 21.0 (Statistical Package for Social Sciences) programına girilerek istatistiksel çalışması yapıldı. İstatistiksel olarak iki grup arasındaki ilişkiyi belirlemek için Ki-kare testi kullanıldı. $\mathrm{p}<0.05$ istatistiksel olarak anlamlı kabul edildi.

Çalışma Hatay Mustafa Kemal Üniversitesi Girişimsel Olmayan Klinik Araştırmalar Etik Kurul Başkanlığı'nın 14.01.2021 Tarih ve 22 sayılı kararı ile onaylandı ve yapıldı.

\section{Bulgular}

Venöz hava embolisi yönünden retrospektif olarak incelenen 1654 kontrastl toraks BT tetkikinin 52'sinde (\%3.14) insidental venöz hava embolisi tespit edildi. Hastaların 19'u (\%36.54) kadın, 33'ü (\%63.46) erkek hasta idi. Hastaların yaş aralığı 20 ile 93 arasında olup yaş ortalaması $60.54 \pm 16.78$ idi. Hastaların 27'sinde sağ koldan, 25'inde sol koldan kontrast madde verilmiş idi. 6 hastada multiple lokalizasyonda hava embolisi tespit edildi (4 hastada 2 lokalizasyonda, 1 hastada 3 
lokalizasyonda ve 1 hastada 4 lokalizasyonda) (Resim 1). 52 hastada toplam 61 seviyede (\%3.68) intravenöz hava tespit edildi. 61 hava embolisinin 30'u (\%1.81) ana pulmoner arterde, 11'i (\%0.66) sol brakiosefalik vende, 4'ü (\%0.24) să brakiosefalik vende, 6's1 $(\% 0.36)$ sol subklavyen vende, 4'ü $(\% 0.24)$ sağ subklavyen vende, 3 'ü $(\% 0.18)$ sağ ventrikülde ve 3 'ü (\%0.18) sağ atriumda tespit edildi (Tablo 1). 52 hastanın 41 'inde (\%2.5) küçük, 9'unda orta $(\% 0.5)$ ve 2 'sinde $(\% 0.12)$ büyük hava embolisi görüldü (Tablo 2 , Resim 2). Kontrast maddenin verildiği kol yönünden yapılan istatistiksal analizde $\mathrm{p}$ değeri 0.148 bulumuş olup anlamlı fark izlenmedi $(\mathrm{p}>0.05)$.

Tablo 1. Hava embolisinin görüldüğü lokalizasyonlar ve kontrast maddenin verildiği yön.

\begin{tabular}{lccc}
\hline Emboli Lokalizasyon & Kontrast maddenin verildiği yön & p değeri \\
\hline & Sağ & Sol & 0.148 \\
\hline Ana pulmoner arter & 14 & 16 & \\
Sol brakiosefalik ven & 5 & 6 & \\
Sol subklavyen ven & & & \\
Sağ brakiosefalik ven & 4 & 1 & \\
Sağ subklavyen ven & 4 & & \\
Sağ ventikül & 2 & \\
\hline Sağ atrium & 3 & \\
\hline
\end{tabular}

Tablo 2. Hava embolisi büyüklük sınıflaması.

\begin{tabular}{lcc}
\hline Emboli tipi & Hava embolisi çapı (cm) & Hava embolisi sayısı \\
\hline & $<1$ & $1-3$ \\
Küçük & $1-2$ & $>3$ \\
Orta & $>2$ & Sayıya bakılmaksızın \\
Büyük & & \\
\hline
\end{tabular}
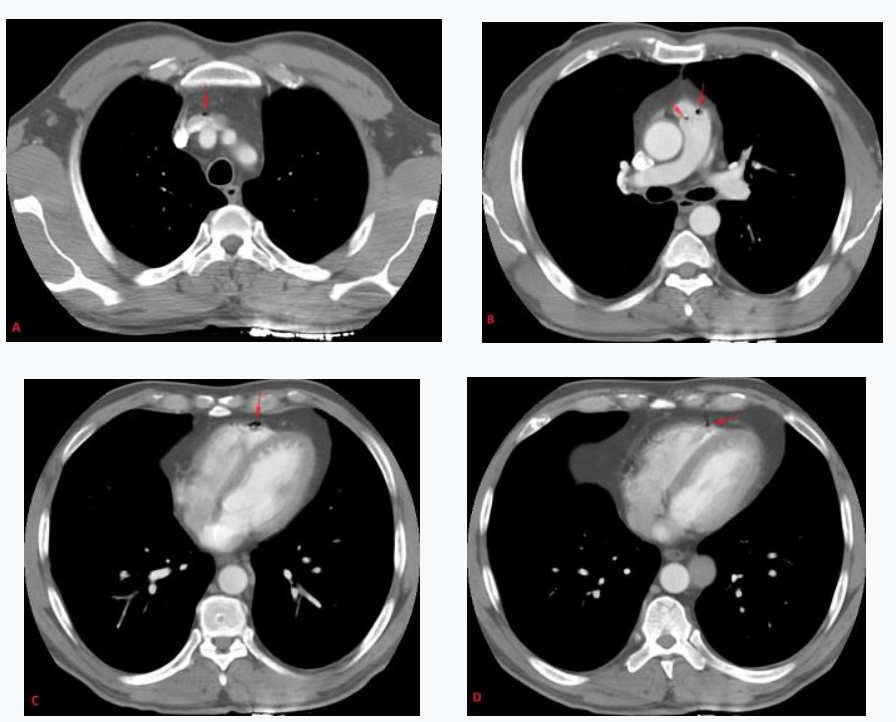

Resim 1. Aynı hastada sol brakiosefalik ven (A), ana pulmoner arter (B), sağ atrium (C) ve sağ ventrikül (D) olmak üzere 4 farklı lokalizasyonda orta büyüklükte venöz hava embolisi. 


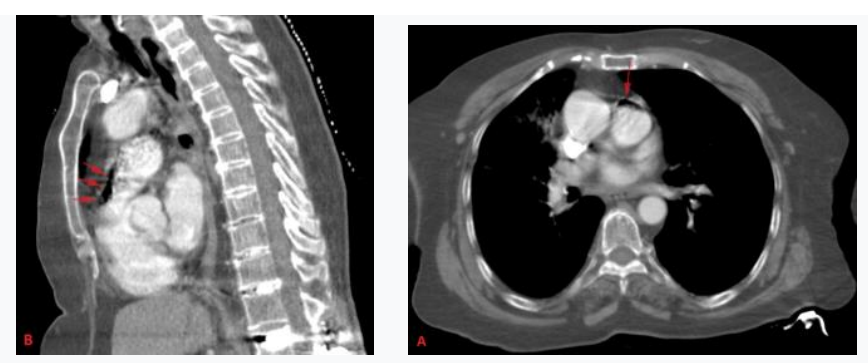

Resim 2. Ana pulmoner arterde büyük venöz hava embolisi aksiyel (A) ve sagittal (B) BT görüntüsü.

\section{Tartışma}

Hava embolisi dolaşım sistemine gaz girişiyle oluşmaktadır. $\mathrm{Bu}$ durum birçok medikalcerrahi durumlarda ortaya çıkabilir. Bu durum intravenöz girişime yada intravenöz infüzyona sekonder oluşuyorsa intravenöz hava embolisi olarak tanımlanır (1). Kontrast madde enjeksiyonu sonrası olabilecek subklinik VHE'ni BT tarama ile tespit etmek, hava volümünü analiz etmek mümkündür.

Kontrastlı BT sırasında oluşan VHE giderek artan bir oranda non fatal bir olay olarak raporlanmaya başlanmıştır. Literatürde postkontrast BT'de nonfatal VHE ile ilgili birkaç tane çalışma mevcuttur. Woodring ve ark'larının (2) yaptığ 1 çalışmada kontrastlı toraks BT sonras1 VHE insidansinı \%23 olarak bulmuşlardır. Groell ve ark 'ları (3) ise kontrastlı BT sonrası \%11.7 oranında ve kontrastsız taramada ise \%5.5 oranında VHE tespit etmişlerdir. Sodhi ve ark'larının (7) 200 hasta ile yaptıkları prospektif çalışmada ise toraks BT'lerin \%7'sinde insidental VHE tespit etmişlerdir. X. Jia ve ark.' larının (6) yaptığı çalışmada kontrastlı koroner anjiografide VHE insidansinı \%4.65 oranında bulmuşlardır. Biz retrospektif olarak yaptığımız çalışmamızda kontrastlı toraks BT incelemesinde kontrast madde enjeksiyonu sonras1 insidental VHE insidansını \%3.1 oranında literatürdeki oranlardan daha az bulduk.

Groell ve ark.'larının (3) elektron-beam BT ile 677 hastada yaptıkları geniş seride VHE en sık ana pulmoner arterde (\%8) bulmuşlardır. Diğer lokalizasyonlar ise sıklık sırasına göre superior vena kava, sağ ventrikül, subklavyen veya brakiosefalik ven ve sağ atriumdur. Sodhi ve ark'larının (7) yaptıkları çalışmada ise en sık ana pulmoner arterde görülmüş olup sol brakiosefalik ven, sağ atrial apendiks ve superior vena kava da VHE tespit etmişlerdir. Bizim çalışmamızda da literatür ile benzerlik göstererek VHE'sini gördüğümüz en s1k lokalizasyon ana pulmoner arterdir (\%1.8). Diğer lokalizasyonlar ise sağ-sol brakiosefalik ven, sağ-sol subklavyen ven, sağ atrium ve sağ ventriküldür.

Küçük venöz emboliler çoğu zaman kan veya akciğerde alveollerden absorbe olur. Hastalar genellikle asemptomatiktir veya dispne gibi nonspesifik bulgulara neden olabilir. Fakat daha büyük emboliler sağ ventrikül çıkışını tıkayarak dolaşım yetmezliğine neden olabilir. Masiv VHE (200-300 ml hava) fatal kabul edilir (8). Bununla birlikte Pham ve ark.'ları (9) kontrastlı BT çekimi sırasında $135 \mathrm{ml}$ venöz sisteme hava girişi olan 2 hastada nonfatal seyrettiği vaka bildirmişlerdir. Sepmtomatik VHE'sinde yaygın olmayan klinik bulgular akut nefes dalığı, göğüs ağrısı, siyanoz, hipotansiyon, pulmoner ödem, paralizi ve nöbettir. Venöz sistemdeki VHE' sinin bulgu şiddeti total hava miktarı, dolaşım sistemindeki pozisyonu ve etkilenen hastanın genel sağlık durumuna bağlıdır (10). Amerikan Radyoloji Kolej'i (ACR) 2017'de hava embolisi ve kontrast madde ekstravazayonu sonucu oluşabilecek potansiyel komplikasyonları önlemek için radyoloji personelinin doğru teknikle kontrast maddeyi vermesi gerektiğini belirtmiştir. (11). Bununla birlikte bu konuda hala belli bir standart bir prosedür yoktur. VHE non fatal iken küçük bir arterial veya pulmoner hava embolisi miyokard enfarktüsü nedeniyle ciddi doku hasarına ve iskemiye ve hatta ölüme 
neden olabilir (12). Bu nedenle radyologlar ve radyoloji teknisyenleri tespit edilen hava miktarı çok az olsa bile çok dikkatli olmalilardir.

Sodhi ve ark.'larının (7) yaptığı 200 hastalık çalışmada iatrojenik venöz hava embolisi ile kontrast miktarı, akım hızı, intravenöz damar yolu boyutu ve hangi taraftan enjeksiyon yapıldığı ile yaptıkları analizde $\mathrm{p}$ değeri anlamlı çıkmamıştır. Price ve ark'ları (13) yaptıkları çalışmada ise başınçlı verilen kontrast madde enjeksiyonu ile büyük venöz hava embolisinin miktarının artırdığını bildirmişlerdir.

Yüksek kontrast madde konsantrasyonu nedeniyle oluşan beam-hardening artefaktı (1şın demetinin sertleşmesi) büyük venlerde yanılgilara neden olabilir. Beam-hardening nedeniyle oluşan düşük atenüasyon alanları özellikle santral venlerde hava kabarcığı varmış gibi görüntüye neden olabilir. $\mathrm{Bu}$ teknik artefakt görüntü iş istasyonlarında dansite ayarı yapılarak yanılgılar ortadan kaldırılabilir (7).

Atrial veya ventriküler septal defekt, arteriovenöz malformasyon, patent foramen ovale VHE'nin arteryal dolaşıma geçişine neden olarak komplikasyon riskini artırmaktadır. Komplikasyonlar serebral (akut-fokal nörolojik defisit veya generalize/global ensefalopati) veya koroner

\section{KAYNAKLAR}

1. Lanfranco J, Romero LI, Freire AX, et al. Pulmonary Air Embolism: An Infrequent Complication in the Radiology Suite. Am $J$ Case Rep. 2017;18:80-4.

2. Woodring JH, Fried AM. Nonfatal Venous Air Embolism After Contrast-Enhanced CT. Radiology. 1988;167:405-7.

3. Groell R, Schaffler GJ, Rienmueller R, et al. VascularAir Embolism: Location, Frequency, And Cause On ElectronBeam CT Studies Of The Chest. Radiology. 1997;202:459-62. embolizm (daha az sıklıkta) ile sonuçlanabilir. Serebral dolaşımdaki havayı tespit etmek veya daha sonra ortaya çıkabilecek fokal enfarktları değerlendirmek için beyin BT taraması gerekir $(14,15)$.

Küçük ve orta VHE'sinde tedaviye gerek yoktur. Şiddetli VHE' sinde hastalar sol lateral dekubit ve trendelenburg pozisyonuna getirilerek (Durant manevrasi) hava kabarcığını sağ ventrikül apeksinde tutarak sağ ventrikül çıkış yoluna hava girişi azaltılmalıdır. Bu manevra ayrica pulmoner arterdeki hava embolisini en aza indirir. \%100 oksijen tedavisi vasküler sistemde sıkışmış havanın emilimini kolaylaştııır (16).

Çalışmamızın limitasyonları retrospektif olması, çalışmaya sadece kontrastlı toraks BT incelemelerin dahil edilmesidir.

\section{Sonuc}

Radyologlar BT taramada yaygin, benign iatrojenik bir bulgu olan venöz hava embolisinin farkında olmalıdır. Küçük hava embolisi asemptomatik olmakla beraber orta ve büyük hava embolisi klinik yönden takip edilmelidir. BT taramada infüzyon şişesinde, damar yolu kanülünde serbest hava varlığını tespit edip müdahale etmek oluşabilecek iatrojenik venöz hava embolisini azaltacaktır.

4. Rubinstein D, Dangleis K, Damiano TR. Venous Air Emboli Identified On Head And Neck CT Scans. J Comput Assist Tomogr. 1996;20:559-62.

5. Sodhi KS, Das PJ, Malhotra P, et al. Venous Air Embolism After Intravenous Contrast Administration For Computed Tomography. $J$ Emerg Med. 2012;42:450-1.

6. Jia X, Li X, Li J, et al. Reducing The Incidence Of Venous Air Embolism In Contrast-Enhanced CT Angiography Using Preflushing Of The Power Injector. Clin Radiol. 2020;75:479.e1479.e7. 
7. Sodhi KS, Saxena AK, Chandrashekhar $\mathrm{G}$, et al. Vascular Air Embolism After Contrast Administration On 64 Row Multiple Detector Computed Tomography: A Prospective Analysis. Lung India. 2015;32:216-9.

8. Yeakel AE. Lethal Air Embolism From Plastic Blood-Storage Container. JAMA. 1968;204:267-9.

9. Pham KL, Cohen AJ. Iatrogenic Venous Air Embolism During Contrast Enhanced Computed Tomography: A Report Of Two Cases. Emerg Radiol. 2003;10:14751.

10. Mirski MA, Lele AV, Fitzsimmons L, et al. Diagnosis And Treatment Of Vascular Air Embolism. Anesthesiology. 2007;106:164-77..

11. ACR. ACR manual on contrast media. In: ACR committee on drugs and contrast media; 2017. Available at: https://www.braccoimaging.com/ sites/braccoimaging.com/files/technica_s heet_pdf/us-en-2018-01-26- manualACR-Contrast-Media.pdf. [Accessed 31 May 2017].

12. Rahman A, Jayasinghe R, Rajendran S. Paradoxical Embolism Via A Patent Foramen Ovale: An Important Mechanism Of Cryptogenic Strokes. Circ Cardiovasc Imaging. 2008;1:e9-e10.

13. Price DB, Nardi P, Teitcher J. Venous Air Embolism As A Complication Of Pressure Injection Of Contrast Media: CT Findings. J Comput Assist Tomogr. 1987;11:294-5.

14. Gronert GA, Messick JM, Cucchiara RF, et al. Paradoxical Air Embolism From A Patent Foramen Ovale. Anesthesiology. 1979; 50: 548-49.

15. Black M, Calvin J, Chan KL, et al. Paradoxic Air Embolism In The Absence Of An Intracardiac Defect. Chest. 1991; 99: 754-5.

16. Gorsi U, Sodhi KS, Yadav BS, et al. Air In Unusual Location After ContrastEnhanced Computed Tomography. Lung India. 2015;32:644-5. 